\title{
栚 \\ Solvent extraction and separation of hafnium from zirconium using Ionquest 801
}

\author{
by L. de Beer*, D.J. van der Westhuizen*, and H.M. Krieg*
}

\section{Synopsis}

The solvent extraction (SX) characteristics of Ionquest 801 were investigated to determine if the selective extraction of hafnium (Hf) over zirconium $(\mathrm{Zr})$ is possible. Firstly, Ionquest 801 was screened for its suitability as a function of acid concentration. The solvent consisted of $5 \mathrm{wt} \%$ extractant, corresponding to a extractant to metal ratio $\left(\mathrm{E}: \mathrm{M}_{\mathrm{Zr}}\right)$ of $14: 1$, in cyclohexane with $5 \% \mathrm{v} / \mathrm{v} 1$-octanol added as modifier. Aqueous solutions of $\mathrm{ZrCl}_{4}$ with $3 \mathrm{wt} \% \mathrm{HfCl}_{4}$ were prepared by dissolution of the salts in $\mathrm{HNO}_{3}$ to obtain $1.0 \mathrm{~g} / \mathrm{l} \mathrm{Zr}(\mathrm{Hf}) \mathrm{Cl}_{4}(\mathrm{aq})$ feed solutions (aged 24 hours). Subsequently, the extractant concentration was varied at optimal acid molarities. The most favourable extraction percentages were attained at $0.7 \mathrm{M} \mathrm{HNO}_{3}$ and an $\mathrm{E}: \mathrm{M}_{\mathrm{Zr}}$ ratio of 5:1. Artifices in the form of aqueous additives were used to maximize the $\mathrm{Hf}$ selectivity at these optimal conditions. These included the addition of $1.5 \mathrm{M} \mathrm{NaCl}, \mathrm{NaNO}_{3}, \mathrm{Na}_{2} \mathrm{SO}_{4}$, and $\mathrm{NaClO}_{4} \cdot \mathrm{H}_{2} \mathrm{O}$, as well as tartaric, oxalic, mandelic, and citric acid with and without the addition of $6 \mathrm{wt} \%$ hydrogen peroxide $\left(\mathrm{H}_{2} \mathrm{O}_{2}\right)$. Exploratory studies on the influence and usability of the most promising factors such as $\left[\mathrm{SO}_{4}^{-2}\right],\left[\mathrm{H}_{2} \mathrm{O}_{2}\right]$, and combinations thereof in a SX system were undertaken.

Keywords

solvent extraction, Ionquest 801, PC88A, organophosphorus, hafnium, zirconium. operation, as well as in the manufacturing process itself. While $\mathrm{Zr}$ for use in the nuclear industry needs to contain less than $100 \mathrm{ppm}$ $\mathrm{Hf}$, various aspects of metal procurement, purification, and production have to be taken into account to make zirconium alloy of the highest grade. The $<100 \mathrm{ppm} \mathrm{Hf}$ requirement is likely to be replaced soon by an American equivalent, Zircaloy-4; or Russian equivalent, $\mathrm{Zr}-1 \% \mathrm{Nb}$. These zirconium alloys, which are already in use in nuclear reactors, contain $\mathrm{Hf}$ concentrations as low as $42 \mathrm{ppm}$ and $80 \mathrm{ppm}$ respectively (Nikulina and Malgin, 2008).

The main impurities found in nucleargrade $\mathrm{Zr}$ are titanium (Ti), boron (B), cadmium (Cd), cobalt (Co), manganese (Mn), molybdenum (Mo), sodium ( $\mathrm{Na}$ ), magnesium $(\mathrm{Mg})$, silicon (Si), carbon $(\mathrm{C})$, hydrogen $(\mathrm{H})$, chlorine $(\mathrm{Cl})$, potassium $(\mathrm{K})$, calcium $(\mathrm{Ca})$, fluorine $(\mathrm{F})$, phosphorous $(\mathrm{P})$, oxygen $(\mathrm{O})$, nitrogen $(\mathrm{N})$, iron $(\mathrm{Fe})$, nickel (Ni), chromium $(\mathrm{Cr})$, copper $(\mathrm{Cu})$, aluminum ( $\mathrm{Al})$, and hafnium (Hf). The most is known about the effects of $\mathrm{O}, \mathrm{N}, \mathrm{H}, \mathrm{C}, \mathrm{Si}, \mathrm{Al}, \mathrm{Fe}, \mathrm{Ni}$, and Hf. The presence of $\mathrm{N}, \mathrm{C}, \mathrm{Al}$, and Ti results in decreased corrosion resistance (in high-temperature aqueous environments), while the presence of $\mathrm{C}, \mathrm{H}, \mathrm{Si}, \mathrm{Cl}, \mathrm{P}$, and $\mathrm{F}$ results in decreased fracture toughness and, as a result, poor manufacturability and cracking resistance of parts. Oxygen improves the strength of zirconium alloys, while Fe improves corrosion resistance. Ni intensifies hydrogen absorption, which in turn decreases fracture toughness. The detrimental effects of impurities on the properties of zirconium alloys are synergistic.
* Chemical Resource Beneficiation, North-West University, Potchefstroom, South Africa.

(C) The Southern African Institute of Mining and Metallurgy, 2016. ISSN 2225-6253. This paper was first presented at the, Nuclear Materials Development Network Conference 2015, Nelson Mandela Metropolitan University, North Campus Conference Centre, Port Elizabeth, South Africa. 


\section{Solvent extraction and separation of hafnium from zirconium using Ionquest 801}

Consequently, concentrations of impurities relative to $\mathrm{Zr}$ as well as to other impurities are important. The performance of zirconium alloys therefore depends not only on the thermonuclear properties, but also on the: microstructure, porosity, fracture toughness, and plasticity, as well as residual plasticity (Nikulina and Malgin, 2008).

The South Africa Nuclear Energy Corporation (NECSA) processes South African zircon ore via a plasma dissociated zircon (PDZ) process and reports that the following impurities are present after the plasma fluorination process: Hf, Si, Fe, Ti, Al, Cr, Mg, Ca, P, U, Th, Fe, Ti, Al, Cr, Mg, Ca, $\mathrm{U}$, and Th. The impurities are present at this stage as oxide and fluoride complexes.

Once the abovementioned impurities have been removed, the production of pure $\mathrm{Zr}$ remains difficult, due to the presence of $0.5-3 \mathrm{wt} \% \mathrm{Hf}$ impurity in the original ore (Belousova et al., 2002). The difficulty originates from the chemical similarities of $\mathrm{Zr}$ and $\mathrm{Hf}$ in both metallic and compound form. The most well-known methods of separation include extractive distillation (CEZUS Process, with a separation factor (SF) of approximately 2 (Banda and Lee, 2015) and solvent extraction (SX) using MIBK (SF approx. 7) or TBP (SF approx. 10) (Banda and Lee, 2015). Many alternative methods have been investigated and are summarized in the following paragraphs.

Fritz and Frazee (1965), applied reversed-phase chromatographic separation to solutions containing 250 and $50 \mu$ mole $\mathrm{Zr}$ and $\mathrm{Hf}$, respectively, and successfully purified $\mathrm{Zr}$ to $0.001-0.002 \% \mathrm{Hf}$ content. The quantitative separation was obtained using Teflon- 6 as solid support and methyl isobutyl ketone, pre-equilibrated with $3 \mathrm{M}$ thiocyanic acid, as the stationary phase. $\mathrm{Zr}$ was eluted with an ammonium thiocyanate-ammonium sulphate solution and Hf stripped from the column with an ammonium sulphate or sulphuric acid solution. Successful column separations were also achieved on solutions containing $\mathrm{Zr}$ to $\mathrm{Hf}$ ratios of 5, 25, and 100 to 1 , with resulting impurity levels of $0.01 \% \mathrm{Hf}$ (in $\mathrm{Zr}$ ) and $0.01 \% \mathrm{Zr}$ (in $\mathrm{Hf}$ ).

Akl et al. (2001) demonstrated that with separationflotation $0-20 \times 10^{-5} \mathrm{~mol} / \mathrm{L}$ of both $\mathrm{Zr}$ and $\mathrm{Hf}$ could be completely separated using an aqueous solution of $\mathrm{HCl}$ at $\mathrm{pH}$ 2 containing Eriochrome Cyanine R (ECR) and an organic solution of the oleic acid surfactant HOL in kerosene. The suggested application of this technique was the separation and microdetermination of $\mathrm{Zr}$ and $\mathrm{Hf}$ in water samples.

Poriel et al. (2006), reported a selectivity $(\alpha)$ of $\geq 2.5$ on a $27 \mathrm{mmol} \mathrm{Zr}$ and $11 \mathrm{mmol} \mathrm{Hf}$ mixed solution, with ligandenhanced separation via ultra/nano-filtration membranes. The best results were obtained with the organic thin-film composite nanofiltration membrane Desal G10 (Osmonics). As EDTA-Hf complexes have a higher thermodynamic stability constant than Zr-EDTA complexes, ethylenediaminetetraacetic acid (EDTA) was used as depolymerization agent. The mechanism of separation is the transport of the EDTA-Hf complexes, which form preferentially, across the membrane.

Smolik et al. (2009) utilized $6.5 \mathrm{~g}$ Diphonix ${ }^{\circledR}$ resin (containing diphosphonic, sulphonic, and carboxylic acid groups) for the separation of $\mathrm{Zr}$ from $\mathrm{Hf}$ in aqueous sulphuric acid medium $(0.5 \mathrm{M})$ containing $6.38 \mathrm{~g} / \mathrm{l} \mathrm{Zr}$ and $0.154 \mathrm{gl} \mathrm{Hf}$. They found that a reduction in temperature $\left(22^{\circ} \mathrm{C}\right.$ to $\left.5^{\circ} \mathrm{C}\right)$ decreased the degree of separation while lower column flow rates increased the extent of separation. Under these conditions, a 10 -fold decrease (from $2.4 \%$ to $0.24 \%$ ) of $\mathrm{Hf}$ in $\mathrm{Zr}$ was achieved with $45 \%$ recovery of $\mathrm{Zr}$. The results indicated that Diphonix ${ }^{\circledR}$ resin is suitable for the separation of $\mathrm{Zr}$ from $\mathrm{Hf}$ by a continuous ion exchange process.

Li et al. (2011) studied the combination of combustion synthesis and molten-salt electrorefining. $\mathrm{Zr}$ metal was produced containing $\leq 70 \mathrm{ppm}$ Hf through separation by exploitation of the differences in the thermodynamic stabilities of $\mathrm{Zr}$ and $\mathrm{Hf}$ fluorides. Firstly, ZrSi powder was produced by magnesiothermic reduction of $\mathrm{ZrSiO}_{4}$ in an argon atmosphere at a pressure of $2.5 \mathrm{MPa}$. The ZrSi was then arc melted and cast into granules for use as raw material in the electrorefining process.The electrorefining cell consisted of a high-purity LiCl-KCl eutectic (chloride electrolyte; $58.5-41.5 \mathrm{~mol} \%, T_{m}=352^{\circ} \mathrm{C}$ ) and $5 \mathrm{wt} \% \mathrm{ZrF}_{4}$ (electrorefining initiator, $\mathrm{Hf}<0.1 \mathrm{wt} \%$ ). It had a calculated efficiency of $57 \%$.

As can be seen from the above examples, most techniques are limited to analytical use and, however successful, some are not as well suited and easily implemented as others. The purpose of this study was to investigate the separation of $\mathrm{Zr}$ and $\mathrm{Hf}$ by means of SX, specifically focusing on the interaction of the organophosphorus extractant Ionquest 801 with feed concentrations ( $\approx 1 \mathrm{~g} / \mathrm{Z} \mathrm{ZrCl}_{4}$ containing $3 \mathrm{wt} \% \mathrm{HfCl}_{4}$ ) that exhibits extraction behaviour approximately representative of more concentrated (industrial) feed streams ( $\approx 10 \mathrm{~g} / \mathrm{Z} \mathrm{ZrCl}_{4}$ containing $3 \mathrm{wt} \% \mathrm{HfCl}_{4}$ ). The influence of various additives as a means to reverse the obtained selectivities was also studied.

\section{Materials and methods}

\section{Materials and general procedure}

Deionized water ( $\mathrm{pH}$ 7.5) was used throughout (Millipore Milli-Q Plus ${ }^{\circledR}$ Q-pack CPMQ004R1) and all reagents were of analytical grade (see Table I). An aqueous feed was prepared by dissolving $1 \mathrm{~g} / \mathrm{Z} \mathrm{ZCl}_{4}$ plus $3 \mathrm{wt} \% \mathrm{HfCl}_{4}$ in $\mathrm{HNO}_{3}$ or $\mathrm{H}_{2} \mathrm{SO}_{4}$ and ageing for 24 hours prior to extraction. The solvent consisted of cyclohexane (diluent), $5 \% \mathrm{v} / \mathrm{v} 1$-octanol (modifier) and Ionquest 801 at a concentration of $5 \mathrm{wt} \%$ relative to the diluent. The two phases were contacted for 60 minutes in polypropylene containers at temperatures of $26 \pm$ $4^{\circ} \mathrm{C}$ at an organic to aqueous (O/A) volume ratio of unity using a batch extraction set-up with a mechanical agitator oscillating at $330 \mathrm{r} / \mathrm{min}$. All extractions were done in triplicate and the average values noted with a $10 \%$ relative error. The $\mathrm{Zr}$ and $\mathrm{Hf}$ concentrations of the feed were determined before and after extraction using ICP-OES (Thermo Scientific iCAP 6000 Series spectrometer and CETAC ASX 520 Autosampler).

\section{Methods}

\section{Influence of $\mathrm{HNO}_{3}$ concentration}

Using the general procedure described above, the influence of the $\mathrm{HNO}_{3}$ concentration on the extraction performance of Ionquest 801 was determined at $\left[\mathrm{HNO}_{3}\right]=0.01-5.0 \mathrm{M}$. 


\section{Solvent extraction and separation of hafnium from zirconium using Ionquest 801}

\begin{tabular}{|c|c|}
\hline $\begin{array}{l}\text { Table I } \\
\text { Reagents and suppliers }\end{array}$ & \\
\hline Reagent & Supplier \\
\hline $\mathrm{HfCl}_{4}(98 \%)$ & Sigma Aldrich (Cas: 13499-05-3) \\
\hline $\mathrm{ZrCl}_{4}(99.5 \%,<50 \mathrm{ppm} \mathrm{Hf})$ & Sigma Aldrich (Cas: 10026-11-6) \\
\hline $\mathrm{HNO}_{3}(55 \%)$ & Merck \\
\hline $\mathrm{H}_{2} \mathrm{SO}_{4}(95-99 \%)$ & Merck \\
\hline 1-octanol & Sigma Aldrich (Cas: 111-87-5) \\
\hline Cyclohexane & Monitoring \& Control Laboratories (Pty) Ltd \\
\hline Lonquest 801 (2-ethylhexyl phosphonic acid mono-2-ethylhexyl ester) & Chemquest \\
\hline D2EHPA (di-(2-ethylhexyl)phosphoric acid) & Sigma Aldrich (Cas: 298-07-7) \\
\hline $\mathrm{NaCl}(99.5 \%)$ & Associated Chemical Enterprises (Cas: 7647-14-5) \\
\hline $\mathrm{NaNO}_{3}(99.0 \%)$ & Minema \\
\hline $\mathrm{Na}_{2} \mathrm{SO}_{4}$ anhydrous $\mathrm{AR}(99 \%)$ & Minema \\
\hline $\mathrm{NaClO}_{4} \cdot \mathrm{H}_{2} \mathrm{O}(98-100 \%)$ & Riedel-de Haën (Cas: 7791-07-3) \\
\hline Mandelic acid (99\%) & Sigma Aldrich (Cas: 90-64-2) \\
\hline L-(+)-tartaric acid ( $\geq 99.5 \%)$ & Sigma Aldrich (Cas: 87-69-4) \\
\hline Citric acid $(99 \%)$ & Sigma Aldrich (Cas: 77-92-9) \\
\hline Oxalic acid (98\%) & Sigma Aldrich (Cas: 144-62-7) \\
\hline $\mathrm{H}_{2} \mathrm{O}_{2}(30 \%)$ & Rochelle Chemicals \\
\hline
\end{tabular}

\section{Influence of lonquest 801 concentration}

Subsequently, the extraction performance of Ionquest 801 was determined at $\mathrm{E}: \mathrm{M}_{\mathrm{zr}}$ ratios from 0.1:1 to $20: 1$ in both 0.7 and $3 \mathrm{M} \mathrm{HNO}_{3}$.

\section{Influence of carboxylic acids}

The extraction performance of Ionquest 801 was determined with additions of $0.1 \mathrm{M}$ tartaric, oxalic, mandelic, and citric acid in $0.7 \mathrm{M} \mathrm{HNO}_{3}$ and at an $\mathrm{E}: \mathrm{M}_{\mathrm{Zr}}$ ratio of 5:1.

Influence of carboxylic acids in the presence of $\mathrm{H}_{2} \mathrm{O}_{2}$ The extraction performance of Ionquest 801 was determined with the addition of $6 \mathrm{w} \% \mathrm{H}_{2} \mathrm{O}_{2}$ and $0.1 \mathrm{M}$ tartaric, oxalic, mandelic, and citric acid, in $0.7 \mathrm{M} \mathrm{HNO}_{3}$ and at an $\mathrm{E}: \mathrm{M}_{\mathrm{Zr}}$ ratio of $5: 1$.

\section{Influence of salting-out agents}

After optimization of the acid and extractant concentration, the extraction performance of Ionquest 801 was determined with additions of $1.5 \mathrm{M} \mathrm{NaCl}, \mathrm{NaNO}_{3}, \mathrm{Na}_{2} \mathrm{SO}_{4}$, and $\mathrm{NaClO}_{4} \cdot \mathrm{H}_{2} \mathrm{O}$ in $0.7 \mathrm{M} \mathrm{HNO}_{3}$ and at an $\mathrm{E}: \mathrm{M}_{\mathrm{Zr}}$ ratio of 5:1.

Influence of $\mathrm{SO}_{4}^{-2}$ concentration in $0.35 \mathrm{M} \mathrm{H}_{2} \mathrm{SO}_{4}$

The extraction performance of Ionquest 801 was determined with the addition of $0-1.05 \mathrm{M} \mathrm{Na}_{2} \mathrm{SO}_{4}$ in $0.35 \mathrm{M} \mathrm{H}_{2} \mathrm{SO}_{4}$ at an $\mathrm{E}: \mathrm{M}_{\mathrm{Zr}}$ ratio of $5: 1$.

\section{Influence of $\mathrm{H}_{2} \mathrm{O}_{2}$ in $0.35 \mathrm{M} \mathrm{H}_{2} \mathrm{SO}_{4}$}

The extraction performance of Ionquest 801 was determined with additions of $0.6,1.2,1.8,2.4$, and $3 \mathrm{wt} \% \mathrm{H}_{2} \mathrm{O}_{2}$ in $0.35 \mathrm{M} \mathrm{H}_{2} \mathrm{SO}_{4}$ and at an E: $\mathrm{M}_{\mathrm{Zr}}$ ratio of 5:1.

Influence of $\mathrm{E}: \mathrm{M}_{\mathrm{zr}}$ in $0.35 \mathrm{M} \mathrm{H}_{2} \mathrm{SO}_{4}$

The extraction performance of Ionquest 801 was determined at $\mathrm{E}: \mathrm{M}_{\mathrm{Zr}}$ ratios of $1: 1$ to $10: 1$ in $0.35 \mathrm{M} \mathrm{H}_{2} \mathrm{SO}_{4}$.

\section{Results and discussion}

\section{Influence of $\mathrm{HNO}_{3}$ concentration}

From Figure 1, it is clear that the extraction of both metal complexes remained above $97 \%$ over the entire acid concentration range $(0-5 \mathrm{M})$. Although the unselective and high extraction attained could be ascribed to the excess of Ionquest 801 (5 wt\%) used, the results clearly show that Ionquest 801 can extract the metal complexes of both $\mathrm{Zr}$ and $\mathrm{Hf}$ and is thus suitable for further study. It is important to note, however, why this system was chosen to start with. The choice of acid, extractant, and ageing are explained in the paragraphs that follow.

The following are important aspects to consider when optimizing an SX system: type of extractant, ageing, type of acid, and the metal concentration in the feed. Lee et al. (2015) studied two SX systems, consisting of Cyanex 272 and D2EHPA (each 0.01-0.07 M) in 2, 4 and $6 \mathrm{M} \mathrm{H}_{2} \mathrm{SO}_{4}$ solutions for different $\mathrm{Zr} / \mathrm{Hf}$ ratios. They found that both systems selectively extracted $\mathrm{Hf}$ over Zr, irrespective of the

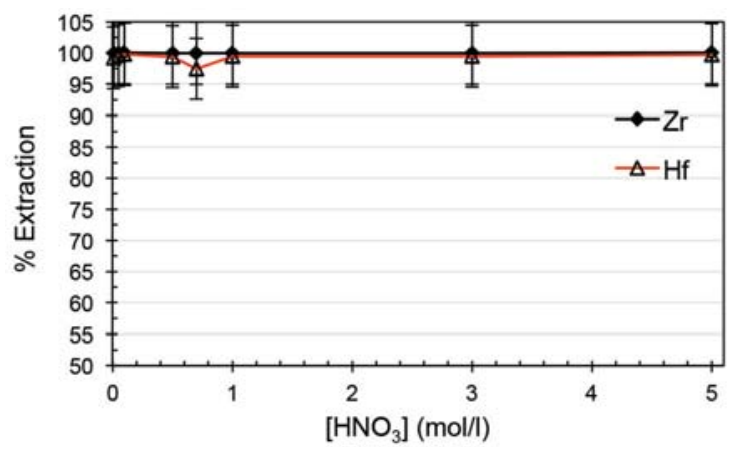

Figure 1-Extraction of $\mathrm{Zr}$ and $\mathrm{Hf}$ as a function of $\mathrm{HNO}_{3}$ concentration 


\section{Solvent extraction and separation of hafnium from zirconium using Ionquest 801}

Zr:Hf ratio (1:1-100:1) with all feed solutions containing $0.2 \mathrm{~g} / \mathrm{l} \mathrm{Hf}$ and the corresponding amount of Zr. Studies have shown that Ionquest 801 not only has a similar structure to D2EHPA, but also similar extraction behaviour. Peppard et al. (1969) found that Ionquest 801 showed significantly higher extraction of $\mathrm{U}(\mathrm{VI})$ compared to D2EHPA. In addition, high extraction has been observed in less acidic environments, with less emulsion formation and improved stripping. Furthermore, Ionquest 801 was used successfully for the separation of higher valence elements or heavy rare earth elements (REE) as well as for group separations of mixtures containing large amounts of heavy REE (Otu and Westland, 1990). It is for these reasons that the separation of $\mathrm{Zr}$ and $\mathrm{Hf}$ was investigated using Ionquest 801.

The reason for ageing the acidic aqueous feed solution was as follows. $\mathrm{Zr} / \mathrm{Hf}$ and $\mathrm{Ta} / \mathrm{Nb}$ systems are similar in that they are neighbouring groups in the same period of the periodic table of elements. While the speciation of these complexes in solution is unknown, research on the SX of the ammonium hexafluorides $\left(\mathrm{NH}_{4} \mathrm{Ta}(\mathrm{Nb}) \mathrm{F}_{6}\right)$ of tantalum $(\mathrm{Ta})$ and niobium $(\mathrm{Nb})$ with D2EHPA and PA in $\mathrm{H}_{2} \mathrm{SO}_{4}$ medium has clearly shown the influence of time on extraction (De Beer et al., 2014). Although D2EHPA in $\mathrm{H}_{2} \mathrm{SO}_{4}$ medium exhibited preferential extraction of Ta over $\mathrm{Nb}$, as in $\mathrm{Hf}$ extraction over $\mathrm{Zr}$ with similar conditions as described above, the amount extracted $\left(\%_{\mathrm{Ta}}\right)$ was stable for only 3.5 hours after acidification of the feed before decreasing from $96 \%$ Ta to $30 \%$ Ta after 24 hours. In view of the similarity between the $\mathrm{Ta} / \mathrm{Nb}$ and the $\mathrm{Zr} / \mathrm{Hf}$ systems, all feed solutions in this study were hence aged for 24 hours before contact with the solvent. This ensures that the feed (solvated complexes) speciation is representative of leach liquors at chemical equilibrium.

The literature indicates that the use of the more corrosive $\mathrm{H}_{2} \mathrm{SO}_{4}$ is favourable. However, $\mathrm{HNO}_{3}$ was chosen to determine whether the manipulation of the SX system with salting-out agents could lead to acceptable extraction values. This would increase safety and applicability to other technologies, e.g. membrane-based solvent extraction (MBSX). The study was conducted on a macroscopic scale with respect to metal concentrations, conditions that would conceivably be encountered on an industrial scale. Hence feed concentrations $\gtrsim 1 \mathrm{~g} / \mathrm{l}\left(\mathrm{ZrCl}_{4}\right)$ containing $3-5 \mathrm{wt} \% \mathrm{HfCl}_{4}$ (relative to $\mathrm{ZrCl}_{4}$ ) were used and assumed to exhibit extraction characteristics representative of more concentrated (industrial) feed streams.

\section{Influence of lonquest 801 concentration}

As no substantial selectivity was obtained towards either complex, irrespective of the concentration of the $\mathrm{HNO}_{3}$ (see Figure 1), the influence of Ionquest 801 concentration on the extraction was investigated at both low $\left(0.7 \mathrm{M} \mathrm{HNO}_{3}\right)$ and high $\left(3.0 \mathrm{M} \mathrm{HNO}_{3}\right)$ acidities. The results are presented in Figures 2 and 3 respectively.

At $0.7 \mathrm{M} \mathrm{HNO}_{3}$, it is clear that there was an initial nearlinear increase in extraction with increasing $\mathrm{E}: \mathrm{M}_{\mathrm{zr}}$ ratio. It is also apparent that Ionquest 801, at low $\mathrm{E}: \mathrm{M}_{\mathrm{Zr}}$ ratios, preferentially extracted $\mathrm{Zr}$, attaining a maximum $\mathrm{Zr}$ extraction (near 100\%) at an $\mathrm{E}: \mathrm{M}_{\mathrm{Zr}}$ ratio of 5:1. Only when the $E: \mathrm{M}_{\mathrm{Zr}}$ ratio reached 15:1 was complete extraction of $\mathrm{Hf}$ observed. This extraction remained practically unchanged for $\mathrm{Zr}$ at both acidities, with $\mathrm{Hf}$ extraction at an E: $\mathrm{M}_{\mathrm{Zr}}$ ratio of 5:1 increasing from $55 \%$ at $3 \mathrm{M}$ to $77 \%$ at $0.7 \mathrm{M}$. Wang and Lee (2014) reported similar findings using PC-88A (the same compound as Ionquest 801 , obtained from Cytec Canada) in $\mathrm{HNO}_{3}$. Varying the $\mathrm{PC}-88 \mathrm{~A}$ concentration at $2 \mathrm{M} \mathrm{HNO}_{3}$ produced a graph exhibiting the same characteristics as those in Figures 2 and 3. Zr extracts preferentially, as shown by the steeper slope, with Hf extraction following roughly the same trend but with lower extraction, until a suitable extractant concentration is reached and both metals extract completely. Direct comparison is, however, not possible as the feed concentrations differed from this study $(0.2 \mathrm{~g} / \mathrm{Zr}+0.2 \mathrm{~g} / \mathrm{l}$ $\mathrm{Hf} v \mathcal{v} .1 \mathrm{~g} / \mathrm{Z} \mathrm{ZCl} 4+3 \mathrm{wt} \% \mathrm{HfCl} 4)$. As a higher selectivity is preferred, the conditions of $0.7 \mathrm{M} \mathrm{HNO}_{3}$ with an $\mathrm{E}: \mathrm{M}_{\mathrm{Zr}}$ ratio of 5:1 were chosen for further optimization.

\section{Influence of carboxylic acids}

Table II shows the effect of four different acidic additives to Ionquest 801 on the extraction of $\mathrm{Zr}$ and Hf. The addition of mandelic acid to the $0.7 \mathrm{M} \mathrm{HNO}_{3}$ feed resulted in the complete precipitation of both metal complexes $\left(99.9 \%_{\text {Metal }}\right.$ precipitation in feed). Tartaric and citric acid both suppress $\mathrm{Zr}$ extraction more than $\mathrm{Hf}$, by a factor of 1.46 and 1.54 respectively. The addition of oxalic acid to the feed rendered both complexes unextractable. These results are surprising, as carboxylic acids and mixtures thereof are often used as extractants themselves (Lee et al., 2004), which would suggest that addition of these acids would increase extraction. The mechanism reported by Lee et al. (2004) was the solvation of the metal complex by two molecules of Versatic acid 10. This would most likely be dependent on the variety of extraction mechanisms present and competition

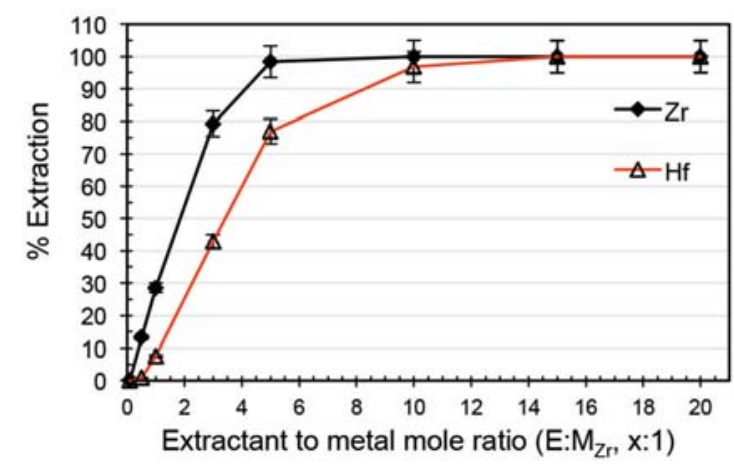

Figure 2-Extraction as a function of lonquest 801 concentration at $0.7 \mathrm{M} \mathrm{HNO}_{3}$

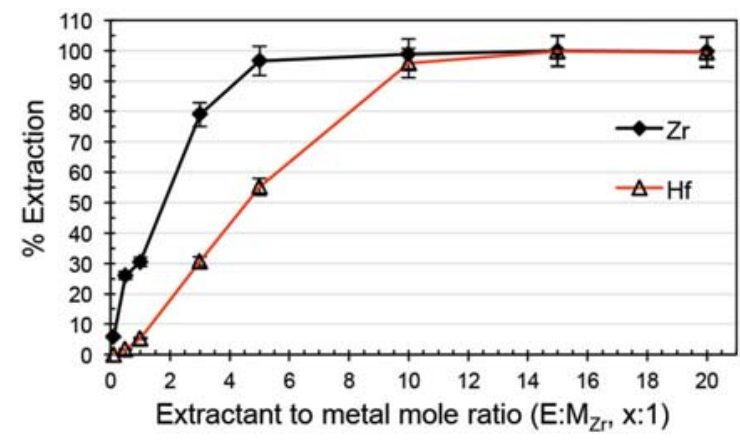

Figure 3-Extraction as a function of lonquest 801 concentration at $3 \mathrm{M}$ $\mathrm{HNO}_{3}$ 


\section{Solvent extraction and separation of hafnium from zirconium using Ionquest 801}

between them. The use of carboxylic acids does, however, seem to be beneficial considering the outcome of the study conducted by Das et al. (1981). They used radio tracers $\left(175,181 \mathrm{Hf},{ }^{95} \mathrm{Zr}\right)$ to optimize a SX system consisting of $0.08 \mathrm{~N}$ $\mathrm{H}_{2} \mathrm{SO}_{4}, 0.1 \mathrm{M}$ carboxylic acid, $6 \mathrm{wt} \% \mathrm{H}_{2} \mathrm{O}_{2}$, and $0.01 \mathrm{M}$ D2EHPA in carbon tetrachloride (CCl4). After extraction with mineral acids, the extraction performance of D2EHPA with organic acids was tested. They found that all the carboxylic acids tested resulted in increased extraction relative to the mineral acids previously tested, including $\mathrm{HCl}$ and $\mathrm{HF}$. In their study, the extractions on the carboxylic acids were carried out in the absence of other acids. Cumulatively, each additive resulted in an Hf-selective SX system, which could be of significance if the principles are applicable to high feed concentrations.

\section{Influence of carboxylic acids in the presence of $\mathrm{H}_{2} \mathrm{O}_{2}$}

The experiments presented above were repeated with the addition of $6 \% \mathrm{H}_{2} \mathrm{O}_{2}$ (Table III) to the aqueous phase. With $\mathrm{H}_{2} \mathrm{O}_{2}$ added, tartaric, mandelic, and citric acid formed organic emulsions after contact with the solvent (organic phase). Only oxalic acid produced results that were similar to those obtained without the addition of $\mathrm{H}_{2} \mathrm{O}_{2}$ (see Table II).

Das et al. (1981) found that the addition of $\mathrm{H}_{2} \mathrm{O}_{2}$ decreases the extraction of $\mathrm{Zr}$, while the $\mathrm{Hf}$ extraction remains unchanged. This effect was most prominent for $\mathrm{HClO}_{4}\left(\%_{\mathrm{Zr}} / \%_{\mathrm{Hf}}=15 / 63\right)$ and $\mathrm{H}_{2} \mathrm{SO}_{4}\left(\%_{\mathrm{Zr}} / \%_{\mathrm{Hf}}=7 / 72\right)$. They ascribed the inability of D2EHPA to extract $\mathrm{Zr}$ in the presence of $\mathrm{H}_{2} \mathrm{O}_{2}$ to the fact that at low acidities, the tendency of $\mathrm{Zr}$ to polymerize is greater than that of Hf. The proposed metal species formed under these conditions is a highly aggregated complex consisting of $\mathrm{Zr}$ metal atoms connected via stable oxygen bonds as bridges between the metal centres. These bridges lead to the formation of $\mathrm{Zr}$ aggregates that are unextractable by the extractant. Considering the strong similarities between $\mathrm{Zr}$ and $\mathrm{Hf}$, it is likely that smaller $\mathrm{Hf}$ aggregates do form, but to a lesser extent. It is likely that these Hf aggregates lead to the formation of emulsions and third phases in the solvent, as the higher feed concentrations enable the formation of larger quantities thereof. The precipitation in the feed, however, is assumed to be due to hydrolysis after the aggregation process is saturated (see section below on the influence of $\mathrm{H}_{2} \mathrm{O}_{2}$ where the extent of the feed precipitation was determined). Thus it seems that the aqueous phase can accommodate both aggregates, with the much smaller Hf aggregates capable of migration to the solvent through extraction with Ionquest 801 . The experimental confirmation of this falls, however, beyond the scope of this paper.

\section{Influence of salting-out agents}

It is known that reaction additives can have a significant effect on the speciation (and hence extraction characteristics) of a metal complex. This principle dates as far back as Le Chatelier, who stated that a system will rearrange itself (partially) to counteract the change in pressure, volume, temperature, or concentration imposed upon it (Kotz and Treichel, 2003). Thus as soon as ions are introduced, the chemical equilibria change, which can be used to influence the SX system. This was demonstrated by Das et al. (1981), who studied the extraction of radio tracers $\left(175,181 \mathrm{Hf},{ }^{95 \mathrm{Zr}}\right)$ with D2EHPA in the presence of various mineral acids. The presence of $\mathrm{SO}_{4}^{-2}$ ions in the feed enables $\mathrm{Zr}$ to form strongly bonded complexes compared to other ions $\left(\mathrm{NO}_{3}^{-}, \mathrm{Cl}^{-}, \mathrm{ClO}_{4}^{-}\right)$, resulting in a decrease in extraction. The best $\mathrm{Hf}$ selectivity was reported using the mineral acids $\mathrm{H}_{2} \mathrm{SO}_{4}, \mathrm{HClO}_{4}$, and $\mathrm{HNO}_{3}$. As dissociated acids release protons and anions, the addition of salting agents might produce the same effect if it is assumed that the acids dissociate completely. To study this, the influence of $\mathrm{NaCl}, \mathrm{NaNO}_{3}, \mathrm{Na}_{2} \mathrm{SO}_{4}$, and $\mathrm{NaClO}_{4}$ was evaluated.

It is clear from Table IV that the best results in terms of an inverse $\mathrm{Hf}$ selectivity were achieved with the addition of $1.5 \mathrm{M} \mathrm{Na}_{2} \mathrm{SO}_{4}$. It is interesting to note that an increase in $\mathrm{NO}_{3}^{-}$ concentration from $0.7 \mathrm{M} \mathrm{HNO}_{3}$ to $2.2 \mathrm{M}\left(0.7 \mathrm{M} \mathrm{HNO}_{3}+\right.$ $1.5 \mathrm{M} \mathrm{NaNO}_{3}$ ) resulted in a suppression of $\mathrm{Hf}$ extraction $\left(\Delta \%_{\mathrm{Hf}}=-16.2\right)$ by a factor of 2.84 , compared to $\mathrm{Zr}$ extraction $\left(\Delta \%_{\mathrm{Zr}}=-5.7\right)$. Conversely, the addition of $1.5 \mathrm{M} \mathrm{Na}_{2} \mathrm{SO}_{4}$ to the feed suppressed $\mathrm{Zr}$ extraction over Hf extraction by a factor of 1.56 , even in the presence of $0.7 \mathrm{M} \mathrm{NO}_{3}^{-}$. As nitrate anions suppress Hf extraction preferentially, the use of nitrate was excluded from this study.

\section{Table /I}

Extraction with carboxylic additives in $0.7 \mathrm{M} \mathrm{HNO}_{3}$ at an $E: M_{z r}$ ratio of $5: 1$

\begin{tabular}{|l|c|c|c|c|}
\hline & Zr, \% & $\Delta \mathbf{Z r}$ & Hf, \% & $\Delta$ Hf \\
\hline No additives & 98.4 & - & 77 & - \\
0.1 M mandelic acid & - & - & - & - a \\
0.1 M tartaric acid & 18.9 & -79.5 & 22.5 & -54.5 \\
0.1 M citric acid & 22.4 & -76.0 & 27.6 & -49.4 \\
0.1 M oxalic acid & 0 & -98.4 & 0 & -77.0 \\
\hline
\end{tabular}

Table III

Extraction with carboxylic acid and $\mathrm{H}_{2} \mathrm{O}_{2}$ in $0.7 \mathrm{M} \mathrm{HNO}_{3}$ at an $\mathrm{E}: \mathrm{M}_{\mathrm{Zr}}$ ratio of $5: 1$

\begin{tabular}{|l|c|c|c|c|}
\hline & $\mathrm{Zr}, \%$ & $\Delta \mathbf{Z r}$ & $\mathrm{Hf}, \%$ & $\Delta \mathbf{H f}$ \\
\hline No additives & 98.4 & - & 77 & - \\
$0.1 \mathrm{M}$ oxalic acid $+6 \% \mathrm{H}_{2} \mathrm{O}_{2}$ & 0 & -98.4 & 0.6 & -76.4 \\
$0.1 \mathrm{M}$ tartaric acid $+6 \% \mathrm{H}_{2} \mathrm{O}_{2}$ & - & - & - & - \\
$0.1 \mathrm{M}$ citric acid $+6 \% \mathrm{H}_{2} \mathrm{O}_{2}$ & - & - & - & - \\
$0.1 \mathrm{M}$ mandelic acid $+6 \% \mathrm{H}_{2} \mathrm{O}_{2}$ & - & - & - & - \\
\hline
\end{tabular}

Table IV

Extraction with the addition of salting-out agents in $0.7 \mathrm{M} \mathrm{HNO}_{3}$ and an $\mathrm{E}: \mathrm{M}_{\mathrm{Zr}}$ ratio of $5: 1$

\begin{tabular}{|l|c|c|c|c|}
\hline & $\mathbf{Z r}, \%$ & $\Delta \mathbf{Z r}$ & $\mathbf{H f}, \%$ & $\Delta \mathbf{H f}$ \\
\hline No additives & 98.4 & - & 77 & - \\
$1.5 \mathrm{M} \mathrm{NaCl}$ & 99.7 & 1.3 & 80.7 & 3.7 \\
$1.5 \mathrm{M} \mathrm{NaNO}_{3}$ & 92.7 & -5.7 & 60.8 & -16.2 \\
$1.5 \mathrm{M} \mathrm{Na}_{2} \mathrm{SO}_{4}$ & 15.3 & -83.1 & 23.7 & -53.3 \\
$1.5 \mathrm{M} \mathrm{NaClO}_{4} \cdot \mathrm{H}_{2} \mathrm{O}$ & 84.4 & -14.0 & 54.7 & -22.3 \\
\hline
\end{tabular}




\section{Solvent extraction and separation of hafnium from zirconium using Ionquest 801}

\section{Influence of $\mathrm{SO}_{4}^{2-}$ concentration in $0.35 \mathrm{M} \mathrm{H}_{2} \mathrm{SO}_{4}$}

In view of the above results it was decided to investigate the characteristics of an $\mathrm{H}_{2} \mathrm{SO}_{4}$-based system instead of the hitherto-used $\mathrm{HNO}_{3}$ system. To maintain the same $\mathrm{H}^{+}$ concentration $(0.7 \mathrm{M})$ the $\mathrm{H}_{2} \mathrm{SO}_{4}$ was used at $0.35 \mathrm{M}$. Considering the dominating strength (in terms of anion displacement and complex stability) of sulphate anion complexes and the polymerization characteristics of $\mathrm{Zr}$ and $\mathrm{Hf}$ at low acidities, ascribing the extraction or lack thereof to any single cause is difficult and beyond the scope of this study. The nature and extent of the polymerization of these metals at low acidities are unknown, and thus the extraction percentage will be considered as the outcome of the cumulative effects of the phenomena present. As can be seen from Figure 4, the presence of $\mathrm{H}_{2} \mathrm{SO}_{4}$ resulted in an inverse selectivity in favour of Hf. Extraction of the metal complexes at these conditions led to an extraction difference of roughly $13 \%$ in favour of $\mathrm{Hf}$, with a $\mathrm{Hf}$ extraction of $39 \%$ and $\mathrm{Zr}$ $26 \%$. It is clear that increasing the sulphate concentration above $0.35 \mathrm{M}$, as dissociated $\mathrm{Na}_{2} \mathrm{SO}_{4}$, decreased the separation and recovery. The resultant drop in extraction for $\mathrm{Hf}$ (from $0.35 \mathrm{M} \mathrm{SO}_{4}^{2-}$ to $0.7 \mathrm{M}$ ) is almost double that of $\mathrm{Zr}$, as the equilibrium driving forces alter the speciation.

This is in good agreement with the results of Banda et al. (2013). Although the experimental conditions varied somewhat in that the feed contained $0.2 \mathrm{~g} / \mathrm{l} \mathrm{Zr}$ and $\mathrm{Hf}$, and D2EHPA was used as extractant, as previously mentioned, D2EHPA and Ionquest 801 have similar extraction behaviours. It is clear from the results of Banda et al. that increased extraction and separation is attained at low acidities $\left(<2 \mathrm{M} \mathrm{H}_{2} \mathrm{SO}_{4}\right)$ rather than high acidities. Note that at low acidities $\left(0.5 \mathrm{M} \mathrm{H}_{2} \mathrm{SO}_{4}\right)$ the extraction of $\mathrm{Hf}$ is roughly double that of $\mathrm{Zr}$, even for the feed $\left(1 \mathrm{~g} / \mathrm{ZrCl}_{4}+3 \mathrm{wt} \%\right.$ $\mathrm{HfCl}_{4}$ ) used with Ionquest 801 at $0.35 \mathrm{M} \mathrm{H}_{2} \mathrm{SO}_{4}$.

From a structural analysis point of view, Hu et al. (2013) combined high-energy X-ray scattering (HEXS), Raman spectroscopy, and mathematical manipulations such as Fourier transformations and Gaussian curves to obtain partial pair distribution functions (PDFs). These PDFs show only those correlations involving $\mathrm{Zr}$ (specifically including those with complexed species, solvent molecules, and other solute ions) and represent electron counts in $\mathrm{Zr}$ ion correlations, enabling possible species to be characterized and elucidated according to relative intensities. Hu et al. (2013, Figure 4) plotted changes in the integrated intensities of selected PDF

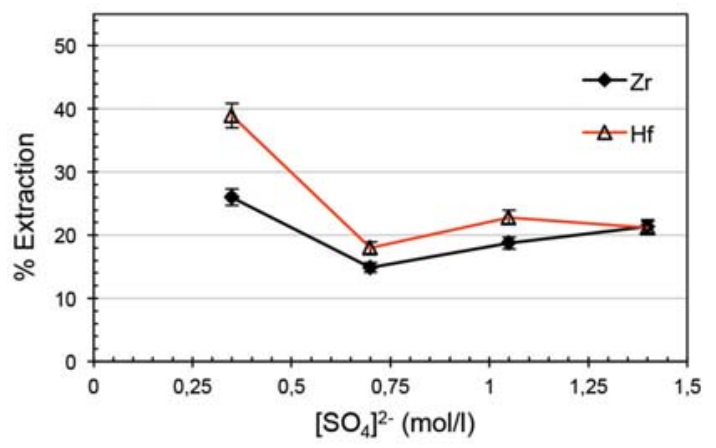

Figure 4-Extraction as a function of sulphate concentration in $0.35 \mathrm{M} \mathrm{H}_{2} \mathrm{SO}_{4}$ at an $\mathrm{E}: \mathrm{M}_{\mathrm{Zr}}$ ratio of $5: 1$ peaks $(3.56,4.97$, and $6.7 \AA)$ as a function of the total sulphate concentration in solution. All three peaks increase in intensity up to $\left[\mathrm{SO}_{4}^{2-}\right]=0.5 \mathrm{M}$ with the peaks at 4.97 and 6.7 $\AA$ having roughly the same intensity and that of $3.56 \AA$ being 2-2.5 times more intense. Hu et al. (2013) interpret this as follows: 'This behavior is suggestive of changing average cluster size across the series, increasing with increasing sulfate concentration up to $0.5 \mathrm{~m}$ in sulfate, and slowly decreasing with higher sulfate concentration.' This then lends merit to the notion that these larger complex clusters may be harder to extract and is likely the reason why extraction is more successful at low acidities and low sulphate concentrations.

\section{Influence of $\mathrm{H}_{2} \mathrm{O}_{2}$ in $0.35 \mathrm{M} \mathrm{H}_{2} \mathrm{SO}_{4}$}

Addition of $\geq 2.4 \% \mathrm{v} / \mathrm{v} \mathrm{H}_{2} \mathrm{O}_{2}$ (as the only additive) to the 0.35 $\mathrm{M} \mathrm{H}_{2} \mathrm{SO}_{4}$ feed led to the formation of aqueous precipitates (after 24 hours ageing). Addition of $\leq 1.8 \% \mathrm{v} / \mathrm{v} \mathrm{H}_{2} \mathrm{O}_{2}$ led to the formation of emulsions after solvent contact. The extent of precipitation was determined in the range of $2.4-4.8 \% \mathrm{v} / \mathrm{v}$ $\mathrm{H}_{2} \mathrm{O}_{2}$. The percentage $\mathrm{Hf}$ precipitated (11.8-40.3\%) is roughly double that of $\mathrm{Zr}(5.2-25 \%)$. It is clear that Hf is hydrolysed more readily than $\mathrm{Zr}$, which is considered to be highly aggregated in this environment. This lends credibility to the notion that at these low acidities the speciation of $\mathrm{Zr}$ and $\mathrm{Hf}$ differs. Thus the capability of $\mathrm{H}_{2} \mathrm{O}_{2}$ to influence the system and metal complex speciation is a dominant process that should be studied further. The formation of stable aggregates, monomers, and dimers (whether from $\mathrm{H}_{2} \mathrm{O}_{2}$ aggregate formation or sulphate-induced polymerization) provide an opportunity for increasing the selectivity of a process, as these might be harder to extract via certain mechanisms. For example, ion exchange requires the exchange of ions between the extractant and the complex, which would not occur if the complex were too stable for this process. The processes of polymerization and aggregation, as well as the extent thereof, are not well documented for $\mathrm{Zr}$ and Hf systems. However, the data presented gives some support to these principles.

We refer again to the system referenced throughout this article. Das et al. (1981) used tartaric acid in their system $\left(0.08 \mathrm{~N} \mathrm{H}_{2} \mathrm{SO}_{4}, 0.1 \mathrm{M}\right.$ tartaric acid, $6 \mathrm{wt} \% \mathrm{H}_{2} \mathrm{O}_{2}$, and $0.01 \mathrm{M}$ D2EHPA in $\mathrm{CCl}_{4}$ ) and observed the preferential extraction of $175,181 \mathrm{Hf}$ over ${ }^{95} \mathrm{Zr}$ (radio tracers) with extraction percentages of $100 \%$ and $1-2 \%$ respectively. This shows that the suppressive effects of $\mathrm{H}_{2} \mathrm{O}_{2}$ and sulphate anions can restrict the extraction of $\mathrm{Zr}$, while the tartaric acid seems to facilitate Hf extraction. These principles seem to be plausible and warrant further investigation.

\section{Influence of $E: M_{z r}$ in $0.35 \mathrm{M} \mathrm{H}_{2} \mathrm{SO}_{4}$}

To improve the recovery and re-evaluate the selectivity at the new parameters obtained from the experiment on the influence of $\mathrm{SO}_{4}^{2-}$ concentration, the extraction performance of Ionquest 801 was determined over a wider range of $\mathrm{E}: \mathrm{M}_{\mathrm{Zr}}$ values.

A comparison of the extraction values in Figure 4 and Figure 5 shows that the selectivity of the process decreased slightly from $\Delta_{\% \mathrm{E}}=13 \%$ (E: $\mathrm{M}_{\mathrm{Zr}}=5: 1$ in $0.35 \mathrm{M} \mathrm{H}_{2} \mathrm{SO}_{4}$ with no addition of $\left.\mathrm{Na}_{2} \mathrm{SO}_{4}\right)$ to $\Delta_{\% \mathrm{E}}=10 \%\left(\mathrm{E}: \mathrm{M}_{\mathrm{Zr}} \geq 3: 1\right.$ in $0.35 \mathrm{M}$ $\mathrm{H}_{2} \mathrm{SO}_{4}$ ). The difference in maximum extraction values at 


\section{Solvent extraction and separation of hafnium from zirconium using Ionquest 801}

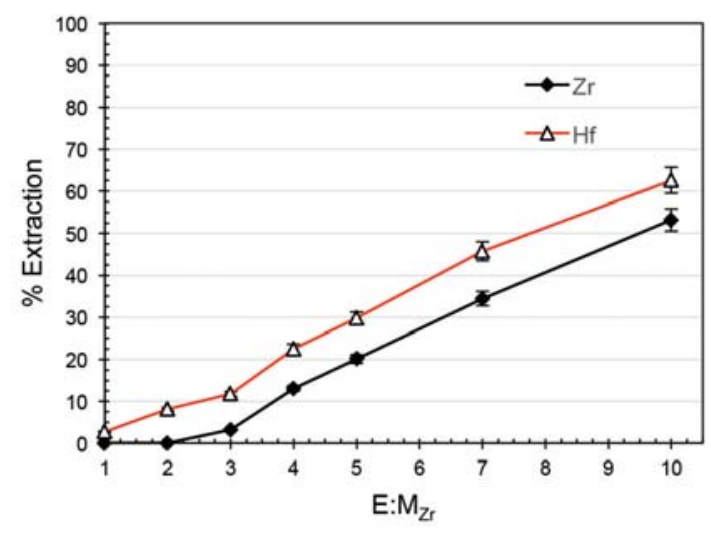

Figure 5-Extraction as a function of $\mathrm{E}: \mathrm{M}_{\mathrm{Zr}}$ ratio in $0.35 \mathrm{M} \mathrm{H}_{2} \mathrm{SO}_{4}$

corresponding points $\left(\mathrm{E}: \mathrm{M}_{\mathrm{Zr}}=5: 1\right)$ of these two figures are most likely due to the values of Figure 5 having been obtained at lower extraction temperatures. From this data it is evident that an $\mathrm{E}: \mathrm{M}_{\mathrm{Zr}}$ ratio 10:1 is already sufficient, with more than $60 \%$ Hf extraction.

\section{Conclusions}

When using $\mathrm{HNO}_{3}$, higher extraction of $\mathrm{Hf}$ was attained at an $\mathrm{E}: \mathrm{M}_{\mathrm{Zr}}$ ratio of $5: 1$ in $0.7 \mathrm{M} \mathrm{HNO}_{3}$ than in $3 \mathrm{M} \mathrm{HNO}_{3}$, with an extraction of $77 \%_{\mathrm{Hf}}$ and $55.2 \%_{\mathrm{Hf}}$ respectively. Zr extraction remained constant $(\geq 97 \%$ Zr $)$ at both acidities. Conditions favouring $\mathrm{Hf}$ extraction (E: $\mathrm{M}_{\mathrm{Zr}}$ ratio of 5:1 in $0.7 \mathrm{M} \mathrm{HNO}_{3}$ ) were therefore set as the basis of the SX system and further investigated. Addition of $1.5 \mathrm{M} \mathrm{Na}_{2} \mathrm{SO}_{4}$ to the system suppressed $\mathrm{Zr}$ extraction preferentially $\left(\Delta \%_{\mathrm{Zr}}=-83.1\right)$ to a value of $15.3 \%_{\mathrm{Zr}}$, while $\mathrm{Hf}$ extraction decreased to $23.7 \%_{\mathrm{Hf}}$ $\left(\Delta \%_{\mathrm{Hf}}=-53.3\right)$. Addition of $1.5 \mathrm{M} \mathrm{NaNO}_{3}$ to the system supressed $\mathrm{Hf}$ extraction preferentially $\left(\Delta \%_{\mathrm{Hf}}=-16.2\right)$ to a value of $60.8 \% \%_{\mathrm{H}}$, while $\mathrm{Zr}$ extraction merely decreased to $92.7 \% \mathrm{Zr}\left(\Delta \%_{\mathrm{Zr}}=-5.7\right)$. This indicated that $\mathrm{NO}_{3}^{-}$ions are detrimental to $\mathrm{Hf}$ extraction and should be excluded from the SX system, while $\mathrm{SO}_{4}^{-2}$ ions are detrimental to $\mathrm{Zr}$ extraction and could be used to supress $\mathrm{Zr}$ extraction preferentially. Nitrate ions were excluded, while maintaining the acidity and sulphate ions, by addition of protons and sulphate ions as $\mathrm{H}_{2} \mathrm{SO}_{4}$ and $\mathrm{Na}_{2} \mathrm{SO}_{4}$. The best salting-out agent tested was $\mathrm{Na}_{2} \mathrm{SO}_{4}$, which was used for further optimization. Carboxylic acids have a suppressive effect (in $0.7 \mathrm{M} \mathrm{HNO}_{3}$ ) on extraction, favouring $\mathrm{Hf}$ extraction. However, this may change significantly with the use of $\mathrm{H}_{2} \mathrm{SO}_{4}$ and addition of $\mathrm{H}_{2} \mathrm{O}_{2}$. It was shown that low acidity $\left(0.7 \mathrm{M} \mathrm{H}^{+}\right.$with the use of $0.35 \mathrm{M} \mathrm{H}_{2} \mathrm{SO}_{4}$ ) resulted in the highest selectivity and recovery of $\mathrm{Hf}$. However, the use of $\mathrm{H}_{2} \mathrm{O}_{2}$ led to feed precipitation or emulsions forming in this batch SX process. The use of a hollow-fibre membrane (MBSX) would avoid emulsions, enabling the use of $\mathrm{H}_{2} \mathrm{O}_{2}$. In addition, the influence of higher $\mathrm{E}: \mathrm{M}_{\mathrm{Zr}}(\geq 5: 1)$ ratios was investigated on the optimized system containing only $0.35 \mathrm{M} \mathrm{H}_{2} \mathrm{SO}_{4}$. An $E: M_{\mathrm{Zr}}$ ratio of 10:1 was sufficient to obtain $\geq 50 \%$ extraction of the solute of interest with an trivial change in selectivity. Acidities below $1.5 \mathrm{M} \mathrm{H}^{+}$(via addition of $\mathrm{HCl}$ ) and anion concentrations below $0.35 \mathrm{M}\left[\mathrm{SO}_{4}^{-2}\right]$ could be further investigated to maximize $\mathrm{Hf}$ recovery and possibly increase selectivity.

\section{References}

AKL, M.A., Kabil, M.A., ABDAllah, A.M., and Ismail, D.S. 2001. Use of eriochrome cyanine $\mathrm{R}$ for separation-flotation and microdetermination of hafnium and zirconium in real samples. Separation Science and Technology, vol. 36, no. 12. pp. 2747-2760.

BANDA, R. and LEE, M.S. 2015. Solvent extraction for the separation of $\mathrm{Zr}$ and Hf from aqueous solutions. Separation and Purification Reviews, vol. 44 no. 3. pp. 199-215.

BANDA, R., Min, S.H., and LeE, M.S. 2013. Selective extraction of Hf(IV) over $\mathrm{Zr}$ (IV) from aqueous $\mathrm{H}_{2} \mathrm{SO}_{4}$ solutions by solvent extraction with acidic organophosphorous based extractants. Journal of Chemical Technology and Biotechnology, vol. 89, no. 11. pp. 1712-1719.

Belousova, E., GrifFin, W.L., O'ReILLY, S.Y., and Fisher, N. 2002. Igneous zircon: trace element composition as an indicator of source rock type. Contributions to Mineralogy and Petrology, vol. 143, no. 5. pp. 602-622.

Chadwick, M.B., Herman, M., OBložInsKÝ, P., Dunn, M.E., Danon, Y., and KaHLER, A.C. et al. 2011. ENDF/B-VII.1 Nuclear Data for Science and Technology: Cross Sections, Covariances, Fission Product Yields and Decay Data. Nuclear Data Sheets, vol. 112, no. 12. pp. 2887-2996.

DAS, N.R., NANDI, B., and BHATTACHARYYA, S.N. 1981. Sequential separation of hafnium, zirconium and niobium from sulphuric acid medium using di(2ethylhexyl) phosphoric acid as an extractant. International Journal of Applied Radiation and Isotopes, vol. 32, no. 4. pp. 205-209.

De Beer, L., Ungerer, M.J., VAn Der Westhuizen, D.J., and Krieg, H.M. 2014. The time dependent solvent extraction of Ta and $\mathrm{Nb}$. Advanced Materials Research. http://www.scientific.net/AMR.1019.433

Fritz, J.S. and FrAzEe, R.T. 1965. Reversed-phase chromatographic separation of zirconium and hafnium. Analytical Chemistry, vol. 37, no. 11. pp. 1358-1361.

Hu, Y-J., Knope, K.E., SKanthaKumar, S., Kanatzidis, M.G., Mitchell, J.F., and SODERHOLM, L. 2013. Understanding the role of aqueous solution speciation and its application to the directed syntheses of complex oxidic $\mathrm{Zr}$ chlorides and sulfates. Journal of the American Chemical Society, vol. 135 , no. 38. pp. $14240-14248$.

Kotz, J.C. and Treichel, J.P.M. 2003. Chemistry and Chemical Reactivity. 5th edn. Thomson Learning. 997 pp.

LEE, H.Y., KIM, S.G., and OH, J.K. 2004. Stoichiometric relation for extraction of zirconium and hafnium from acidic chloride solutions with Versatic acid 10. Hydrometallurgy, vol. 73, no. 1-2. pp. 91-97.

LEE, M.S., BANDA, R., and Min, S.H. 2015. Separation of $\mathrm{Hf}(\mathrm{IV})-\mathrm{Zr}(\mathrm{IV})$ in $\mathrm{H}_{2} \mathrm{SO}_{4}$ solutions using solvent extraction with D2EHPA or Cyanex 272 at different reagent and metal ion concentrations. Hydrometallurgy, vol. 152, no. 0. pp. 84-90.

Li, H., Nersisyan, H.H., Park, K-T., PARK, S-B., Kim, J-G., LeE, J-M., and LEE, J-H. 2011. Nuclear-grade zirconium prepared by combining combustion synthesis with molten-salt electrorefining technique. Journal of Nuclear Materials, vol. 413, no. 2. pp. 107-113.

Nikulina, A.V. and MaLGin, A.G. 2008. Impurities and their effect on the structure and properties of zirconium parts in nuclear reactors. Atomic Energy, vol. 105, no. 5. pp. 328-339.

OтU, E.O. and WeSTLAND, A.D. 1990. Solvent extraction with organophosphonic mono-acidic esters. Solvent Extraction and Ion Exchange, vol. 8, no. 6. pp. 759-781.

Peppard, D., Mason, G., and Lewey, S. 1969. A tetrad effect in the liquid-liquid extraction ordering of lanthanides (III). Journal of Inorganic and Nuclear Chemistry, vol. 31, no. 7. pp. 2271-2272.

Poriel, L., Chitry, F., Pellet-Rostaing, S., Lemaire, M., and Favre-Réguillon, A 2006. Zirconium and hafnium separation, Part 3. Ligand-enhanced separation of zirconium and hafnium from aqueous solution using nanofiltration. Separation Science and Technology, vol. 41, no. 13. pp. 2883-2893.

SMolik, M., JAKóBiK-Kolon, A., and PorańSKI, M. 2009. Separation of zirconium and hafnium using Diphonix ${ }^{\circledR}$ chelating ion-exchange resin. Hydrometallurgy, vol. 95, no. 3-4. pp. 350-353.

SPEER, J.A.C. and COOPER, B. J. 1982. Crystal structure of synthetic hafnon, HfSiO4, comparison with zircon and the actinide orthosilicates. American Mineralogist, vol. 67. pp. 804-808.

WANG, L.Y. and LeE, M.S. 2014. Separation of zirconium and hafnium from nitric acid solutions with LIX 63, PC 88A and their mixture by solvent extraction. Hydrometallurgy, vol. 150, no. 0. pp. 153-160. 